\title{
Characterizing reading comprehension of mathematical texts
}

\author{
Magnus Österholm
}

\section{Linköping University Post Print}

N.B.: When citing this work, cite the original article.

The original publication is available at www.springerlink.com:

Magnus Österholm, Characterizing reading comprehension of mathematical texts, 2006, Educational Studies in Mathematics, (63), 3, 325-346.

http://dx.doi.org/10.1007/s10649-005-9016-y

Copyright: Springer Verlag (Germany)

http://www.springerlink.com/

Postprint available at: Linköping University Electronic Press

http://urn.kb.se/resolve?urn=urn:nbn:se:liu:diva-14117 


\title{
Characterizing reading comprehension of mathematical texts
}

\author{
Magnus Österholm \\ Department of Mathematics, Linköping University, Sweden
}

\begin{abstract}
This study compares reading comprehension of three different texts: two mathematical texts and one historical text. The two mathematical texts both present basic concepts of group theory, but one does it using mathematical symbols and the other only uses natural language. A total of 95 upper secondary and university students read one of the mathematical texts and the historical text. Before reading the texts, a test of prior knowledge for both mathematics and history was given and after reading each text, a test of reading comprehension was given. The results reveal a similarity in reading comprehension between the mathematical text without symbols and the historical text, and also a difference in reading comprehension between the two mathematical texts. This result suggests that mathematics in itself is not the most dominant aspect affecting the reading comprehension process, but the use of symbols in the text is a more relevant factor. Although the university students had studied more mathematics courses than the upper secondary students, there was only a small and insignificant difference between these groups regarding reading comprehension of the mathematical text with symbols. This finding suggests that there is a need for more explicit teaching of reading comprehension for texts including symbols.
\end{abstract}

Key words: literacy, mathematical texts, mental representation, reading comprehension, symbols, university, upper secondary level 


\section{Introduction}

All over the world, textbooks seem to play an important role in mathematics education at all levels (Foxman, 1999), and thereby students’ reading activity and reading comprehension also play important roles. However, if the textbook is mainly used as a collection of given problems or tasks to solve, the reading is limited to the reading of the text of a given task. In such a situation it can be of interest how the reader's comprehension of this (small) text relates to the solving of the task, and Hubbard (1990, p. 265) also claims that "most of the work on reading mathematics has been directed towards improving problem solving skills.” Perhaps it is such a focus on solving given tasks and problems that has caused much of research in mathematics education to reduce reading to a potential obstacle for learning (Borasi and Siegel, 1990, 1994). For example, this can be done by focusing on how limitations in reading ability affect learning in mathematics or on readers' misunderstandings of a written task and how this can influence the solving of the task. The reading of a mathematical text is thereby in itself not seen as an opportunity for learning, but only as a necessary kind of ability in order to become active in situations where learning can take place (i.e., solving given tasks).

However, reading in itself can also be seen as an essential part of mathematics and mathematical knowledge, and not only viewed in relation to other types of activities. For example, Niss and Højgaard Jensen (2002) have characterized mathematical knowledge with eight different competencies, where the competence of communication is one, which includes the ability to interpret and understand mathematical texts. Thereby, reading and reading comprehension could be more explicitly included in mathematics education, in the teaching as well as examinations, and some argue it should be included (Cowen, 1991; Fuentes, 1998; Krygowska, 1969). However, there seems not to be much research done about the more detailed use of mathematical texts in learning situations (Fenwick, 2001; Love and Pimm, 
1996), but more research that focuses on other aspects of mathematics textbooks (see Turnau, 1983). For example, in the Swedish research community there are studies about the solving of textbook exercises (Lithner, 2004), about the role of the textbook as a part of the curriculum (Johansson, 2003), and about differentiation in mathematics textbooks (Brändström, 2005).

In this paper, the reading of a (mathematical) text is seen as an opportunity for learning, and the reading process is studied in order to contribute to our understanding of how and what one can and cannot learn through reading mathematical texts. Therefore, focus is not on texts that include some given task to solve, but on texts that describe and try to explain something to the reader. Also, the reading and comprehension of the texts is not related to the solving of some other task, but focus is on how the reader understands the content of the text itself. The study described in this paper characterizes some aspects of reading and reading comprehension of mathematical texts, in particular what, if anything, is special about reading mathematical texts.

Watkins $(1977,1979)$ had a similar focus in her study of reading comprehension among college students. She used four different types of mathematical texts (using symbols or not and using grammatical structures from ‘mathematical English' or 'ordinary English'), from which she drew the conclusions that: "Symbols do not appear to help or hinder students with limited background in mathematics, and they may help more advanced students. Both groups of students learn better from treatments that use ordinary English structures” (Watkins, 1979, p. 218). Because of the similarities between the present study and Watkins' study, comparisons of results and methods are discussed at the end of this paper. 


\section{Reading mathematical texts}

\subsection{The reading process}

When reading a text, a mental representation of the text is created by the reader, which describes how the reader understands the text. Many studies about reading comprehension show, or support the conclusion, that "multiple levels of representation are involved in making meaning” (van Oostendorp and Goldman, 1998, p. viii). In particular, the work of Walter Kintsch (e.g., see Kintsch, 1994, 1998; van Dijk and Kintsch, 1983) seems to have had a great influence on research on reading comprehension (Weaver et al., 1995).

One way to model both the meaning of text content and mental structure in general (i.e., memory), not only mental representations in relation to texts, is to use associative networks of propositions, which can be viewed as "an important theoretical and methodological advance in text comprehension” (Lorch and van den Broek, 1997, p. 222). An associative network is built up by nodes and links between nodes that "are unlabeled and vary in strength" (Kintsch, 1998, p. 74). A node can be a singular word (which gets its meaning from the existing links to other nodes) or a type of meaning unit (a proposition).

A more detailed description of the mental representation of texts can be created by distinguishing between three different levels, or components, of the mental representation: the surface component, the textbase, and the situation model (Kintsch, 1998). These components are not seen as separated in the mental representation, but they can be useful when describing and characterizing mental representations, and thus function as an analytical tool. It could also be noted that this tool is not directly applicable to mental representations in general, but describes mental representations in relation to a given text. 


\subsubsection{Surface component}

When the words and phrases themselves are encoded in the mental representation (possibly together with linguistic relations between them), and not the meaning of the words and phrases, one can talk about a surface component of the mental representation. A surface component is always present when reading, although to different degrees, since "it is generally the case, that at least some of the exact words and phrases are remembered" (Kintsch, 1998, p. 105), even when understanding the meaning of the text.

\subsubsection{Textbase}

The textbase represents the meaning of the text, that is, the semantic structure of the text, and it "consists of those elements and relations that are directly derived from the text itself [...] without adding anything that is not explicitly specified in the text” (Kintsch, 1998, p. 103). Since the textbase is part of the mental representation, the meaning this network represents is the explicit meaning of the text as it is understood by the reader, which for example may include some reading errors made by the reader. Since the textbase consists of the meaning of the text and the same meaning can be expressed with different formulations, a textbase can be created without any memory of the exact words or phrases from the text. For example, if a person after reading a text including the sentence "The absolute value of a real number is a simple kind of function” is able to answer a question about the relationship between absolute value and function, this shows the existence of (a part of) a textbase. This part of the mental representation does not presuppose an understanding of the concept of function.

\subsubsection{Situation model}

A pure textbase can often be "an impoverished and often even incoherent network" (Kintsch, 1998, p. 103), and to make more sense of the text, the reader must use prior knowledge to create a more complete and coherent mental representation. A construction that integrates the 
textbase and relevant aspects of the reader's knowledge is called the situation model. Some prior knowledge is also needed to create a textbase, but this knowledge is of a more general kind that is needed to "decode" texts in general, while the prior knowledge referred to in the creation of a situation model is more specific with respect to the content of the text.

\subsection{Mathematical texts}

In this study, mathematical texts used in, or at least created for, educational settings that focus on learning mathematics are of interest. Even with this limitation it is not easy to define or describe these texts, and it is even questionable if there is a common core to all texts of interest (Morgan, 1998). A similar problem of definition arises when talking about symbols. Everything written (and much more) can be viewed as symbols, but in this paper, '(mathematical) symbols’ refer to the special symbolic language of mathematics.

One can find much research, both empirical and theoretical, about reading comprehension in general, which does not focus on any particular type of text content. But texts with different content or texts that have different purposes might also differ with respect to structure or other properties, for which readers need to have different reading strategies. A literature survey by Österholm (2004, section 3.1), including 19 references $^{1}$, showed that there exist many beliefs and claims about special properties of mathematical texts, which affect the reading in particular ways, and claims that one needs to read mathematical texts in special ways for comprehension. The survey revealed claims about single words in mathematical texts (e.g., that certain words are used in a complex way), single sentences in mathematical texts (e.g., that the sentence structure is complex), mathematical texts in general (e.g., that the texts have low redundancy), and the reading of mathematical texts (e.g., that one needs to read the texts several times). However, no studies were found that had these claims as a result from either empirical or theoretical research, but many claims were taken for granted as true without a motivation or explanation of any kind. Such statements about mathematical texts and the 
reading of mathematical texts "have little value both theoretically and practically" (Konior, 1993, p. 251). Two additional comments also need to be added about the results of the survey. Firstly, many of the articles studied seem to (often implicitly) equate mathematical texts with texts consisting of symbols. Morgan (1998, p. 13) also notes this existence of a common “identification of mathematics with its symbol system.” Secondly, when claims about special properties of mathematical texts are made, these texts are compared to "ordinary" texts, and no studies were found that compare mathematical texts with texts from some other subject area.

Brunner (1976) highlights the possibility that properties of mathematical texts might be caused either by certain properties of mathematics itself or by how one chooses to present the content. There are some aspects of mathematics itself that might cause mathematical texts to have certain properties. For example, Solomon and O’Neill (1998) claim that properties of mathematics make it impossible to write narrative mathematical texts. The symbol system of mathematics might also cause texts using symbols to have certain special properties. For example, Ernest (1987) argues that the symbolic expressions not only follow different syntactical rules, but also fundamentally different grammatical rules, as compared to natural language.

\subsection{Content literacy}

The concept of literacy is sometimes used "to denote mere knowledgeability of a specific subject (as in computer literacy, cultural literacy, etc.)” (McKenna and Robinson, 1990, p. 184). However, in this paper, content literacy refers to the ability to read, understand and learn from texts from a specific subject area, as it is also defined by McKenna and Robinson (1990). They also distinguish between three components of content literacy: general literacy skills, content-specific literacy skills, and prior knowledge of content. Both the general and the content-specific literacy skills can be assumed to refer to some more general type of 
knowledge that is not dependent on the detailed content of a specific text. This type of knowledge is primarily used to "decode" texts, that is, to create a textbase in the mental representation. But the third component of content literacy, prior knowledge of content, refers to knowledge that is connected to the content of a specific text, and is thus primarily used to create a situation model in the mental representation.

Since there can be properties of mathematics that create certain special properties of mathematical texts, there can be a need for content-specific literacy skills in mathematics. The symbolic language is perhaps the most obvious property of mathematics that might create a need for such literacy skills. To understand a text written purely with mathematical symbols one might not even need general literacy skills, that is, one might not need to know how to 'read' (in the sense perhaps most commonly used, i.e., reading texts written in a natural language). However, the perhaps most common mathematical texts use both the symbolic language and a natural language, where one would seem to need both general and contentspecific literacy skills. But what about mathematical texts that do not contain any symbols at all? Are there other special properties of these texts (since they are mathematical texts) that demand other types of content-specific literacy skills, or would it be enough for the reader to use general literacy skills? These questions are addressed and, at least partially, answered in this paper.

\section{Purpose}

This paper reports on a study to characterize reading comprehension of mathematical texts, to see if and how the subject area in itself (i.e., that a text is a mathematical text) can affect the reading comprehension, or if the comprehension process is more affected by how the content is presented. Two major questions are addressed: 
1. How can reading comprehension of mathematical texts without symbols be characterized compared to reading comprehension of texts from other subject areas? Is there a significant difference caused by some properties of the subject areas themselves, or is the main component of the comprehension process for these texts the general literacy skills?

2. How is reading comprehension affected by the use of symbols in mathematical texts? Can the reading of texts with symbols be seen as a part of the content-specific component of the literacy skills, or are the general literacy skills more important and dominating factors in the reading process?

The use of more specific prior knowledge (in relation to the text content) in the comprehension process is not of interest in this study, but focus is on the more general types of knowledge used when reading a text, that is, focus is on the creation of a textbase in the mental representation. However, since all types of prior knowledge are presumed to affect reading comprehension, also the more specific prior knowledge must be taken into account.

\section{Method}

This study compares reading comprehension among students for three different texts: two mathematical texts and one historical text. The two mathematical texts both present to the reader some basic concepts in group theory (mathematical system and group), but one text does so without using any symbols while the other uses symbols. For the participating students, in the text using symbols, the only new symbol introduced is one for a general rule of combination in a system or group. Besides that, the symbols used are familiar to the students ('=', '+' and variables). See Figure 1 for an example of the differences between the two mathematical texts. 


\section{Text with symbols:}

A group is a mathematical system, i.e., a set $G$ and a rule of combination , which also has the following four properties:

1) If $a$ and $b$ belong to $G$, then $a \sim b$ also belongs to $G$. One says that the system is closed.

\section{Text without symbols:}

A group is a mathematical system, i.e., a set and a rule of combination, which also has the following four properties:

1) If two objects belong to the set, then the combination of these also belongs to the set. One says that the system is closed.

Figure 1. Example of the differences between the mathematical texts. Note that the texts were originally in Swedish, and these excerpts have been translated for this paper.

The historical text describes the events in Russia during the Russian revolutions and it does not use any symbols. One can say that the two mathematical texts have the same content, but present it differently (with or without symbols), while the mathematical text without symbols and the historical text have different content but present it in a similar way (using only natural language). The mathematical texts were created specifically for this study, while the historical text was taken from Vidal-Abarca et al. (2000), but translated into Swedish. All texts take up no more than one page.

A total of 95 students voluntarily participated in this study, 61 from the Swedish upper secondary level (hereafter referred to as S-students) and 34 from the Swedish university level (hereafter referred to as U-students). Originally, five more S-students and one more U-student took part in this study. But since the five S-students did not complete the whole procedure or 
wrote apparent nonsense as answers to questions, and since the one U-student had previously studied group theory, the results from these students were excluded from the data analyzed. ${ }^{2}$

The S-students were at the end of their third and last year of the natural science programme, and they had finished all courses, but not yet received all their grades. They came from four different classes and two different schools. The U-students were studying to become engineers, civil engineers, or teachers. They had all previously studied mathematics equivalent to the natural science programme at the upper secondary level, and had also studied some courses in mathematics at the university level, in algebra and real analysis. These two groups of students were used in order to have participants with varying levels of mathematical prior experience, to be able to study a possible effect such experience might have on reading comprehension.

The participants worked individually with self-instructing material in which the students gave all answers in writing, according to the following procedure:

- Give background information: Grades from mathematics courses.

- General instructions: Work with the material in the given order and to never go back when finished with one part.

- Part 1: Test of prior knowledge in mathematics and history (see section 4.1 for more details).

- Part 2: Reading of the mathematical text. The two different mathematical texts were randomly distributed among participants. Before reading, instructions were given to read the text only once, but thoroughly, and that questions about the content of the text would be given afterwards, in the next part. Thereby the students could not use the text when answering the questions. 
- Part 3: Questions about the content of the mathematical text, that is, a test of reading comprehension (see section 4.2 for more details). Before answering the questions, instructions were given that partial answers also were acceptable, and the participants were instructed to write explanations why an answer, or a complete answer, could not be given.

- $\quad$ Part 4 and part 5: The same as part 2 and part 3, but with the historical text.

There was no given time limit for the participants, and all were finished within approximately one hour.

\subsection{Test of prior knowledge}

The test of prior knowledge consists of ten words, five for mathematics and five for history. For each word, the participants were asked to give their spontaneous thoughts about the meaning of the word, how the word can be used, or other associations to the word. The words used in this test are words also used in the texts, 'addition', 'set', 'inverse', 'definition', and 'integer' for the mathematical texts, and 'tsar', 'proletariat', 'Lenin', 'social class', and 'Bolshevik' for the historical text. Thus, this test is highly specific for the content of the texts used in this study.

The prior knowledge activated during the reading process can be described as associations elicited by the words and statements (meaning units) in the text, that is, nearby nodes in longterm memory are activated (Kintsch, 1998). This way of testing prior knowledge is therefore relevant in relation to reading. In order not to activate any more specific prior knowledge among the participants before reading, free associations to singular words are seen as more appropriate in this study.

To obtain a quantitative measure of prior knowledge, the participants' associations were categorized with respect to the organization of knowledge, as highly, partially, or diffusely 
organized (Langer, 1984). Associations in these categories were given three, two, and one point respectively. Zero points were given to totally irrelevant associations and if no associations were given at all. Thereby, each participant could get 0-15 points as a measure of prior knowledge in each of mathematics and history (five words and three points per word for each subject area).

To ensure that all associations were categorized in the same way, possible examples of the different types of associations were not only created before the analysis, but examples were also added during the analysis from the participants' answers. More specific subcategories (see Langer, 1984) were also used to simplify the analysis. See Figure 2 for examples of

Given word: addition

Highly organized:

Superordinate concepts: rule of arithmetic. Definitions: combining of (two) quantities using the plus operator. Linking: explicitly given relation to other rule of arithmetic (e.g. subtraction).

Partially organized:

Examples: $1+2=3$. Attributes: commutativity. Defining characteristics: plus, put together, add numbers, sum, addends.

\section{Diffusely organized:}

Associations: subtraction. Morphemes: add. First hand experiences: lower primary school, mathematics.

Figure 2. Example from the test of prior knowledge. Note that all descriptions were originally in Swedish, and this example has been translated for this paper. 
descriptions of the categories used in the analysis.

\subsection{Test of reading comprehension}

The test of reading comprehension consists of six questions for the mathematical texts and six questions for the historical text. The same questions were used for both types of mathematical texts. Since the creation of a textbase in the mental representation is of interest in this study, the questions are constructed so that they could be answered with some explicit information given in the text. But in order not to measure pure memorization of the texts (i.e., not to measure the surface component of the mental representation), the questions are not formulated in ways that resemble specific formulations given in the texts. Many questions are also quite open, for example by asking for the meaning of a key concept from the text (applicable for the mathematical texts where the purpose of the texts is to introduce new concepts).

The purpose of asking questions is to get a "picture" of the reader’s mental representation of the text, where each question tells something about the local appearance of the reader's memory around the relevant nodes triggered by the question. Another way to try to observe the mental representation could be to give a single word, and let the reader freely associate to that word in order to get a more genuine picture of the associative network around that particular word. But in order to simplify a quantification of the reading comprehension, specific questions are more suitable.

The manner in which the students' answers were analyzed is schematically described in Figure 3, and a more detailed description of this procedure follows.

To obtain a quantitative measure of reading comprehension, answers for each question were divided in categories that were hierarchically ordered with respect to how complete and correct the answers were in relation to the content of the text. Even if a reader has understood much about what a specific question asks for (i.e., if many nodes and links are present in the 


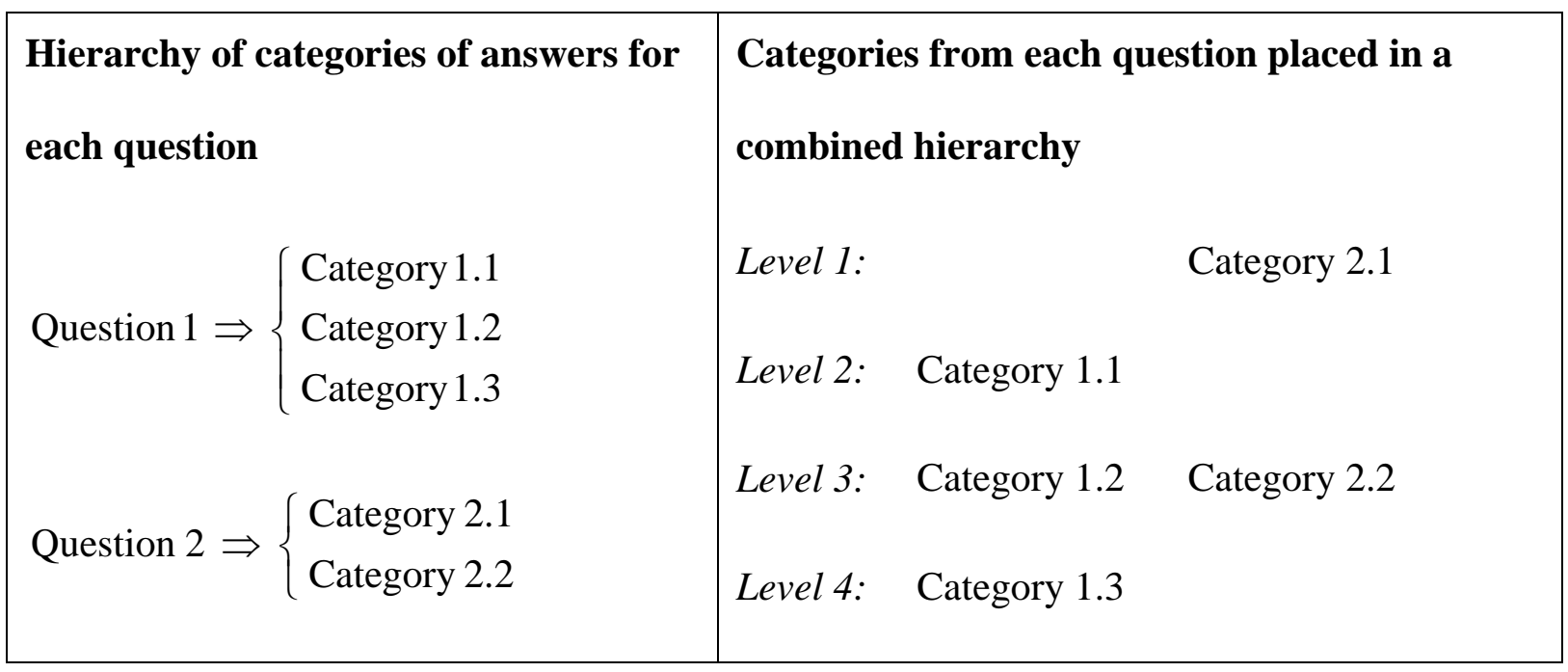

Figure 3. Schematic description of procedure for analysis of students' answers to questions in the test of reading comprehension (se Figure 4 for examples of categories and combined hierarchy).

mental representation), the answer is more likely to be based on the nodes that have the strongest links to the nodes activated by the question. Thereby, the different categories describe differences in the quality of the created textbase in the mental representation.

Categories were created before the analysis, but when analyzing the students' answers, the categories could be altered in order to better describe the differences in comprehension among the participants. This alteration could be to add a student's answer in the description and exemplification of a specific category, to split a specific category into two parts if nuances were found in students' answers within a category, or to join two categories if the intended differences between the categories were too difficult to distinguish in students' answers. If alterations were made to the categories of a question, the already categorized answers were analyzed once again. In this way, the categorization of answers could be performed in a fair and equal manner for all students’ answers.

Separately for mathematics and history, the categories from all questions were compared in order to give points to categories from different questions in the same way. In this 
comparison, the categories were characterized with respect to whether the answer in a specific category referred to comprehension of a central or peripheral part of the text, and with respect to the completeness of the answer. Points were given to the categories in the combined hierarchy, where the lowest category was given one point and then increasing by one point for each level in the hierarchy of categories. Zero points were given to answers that did not fit any category. Each participant could get 0-19 points as a measure of reading comprehension for the mathematical text and 0-26 points for the historical text.

Mathematical question number 3: Is the claim “A mathematical system is a group” true or false? Explain your answer!

Category 3.1: "No, a group is a system" OR gives an example of a system that is not a group, without giving explicit reasons.

Category 3.2: Claims that a group is a system and that a group has properties not all systems have OR gives an example of a system that is not a group, including a property that is missing for it to be a group.

\section{Combined hierarchy:}

Level 1: Answers directly corresponding to a single aspect of the example given in the text or faulty, partly wrong answers corresponding to some more general aspect.

Level 2: Answers corresponding to some general aspect of the given example in the text or more general answers but with a faulty explanation/description.

Level 3: General answers/descriptions, but not totally specified. [Category 3.1]

Level 4: Specified general answers. [Category 3.2]

Figure 4. Example from the test of reading comprehension. Note that all descriptions were originally in Swedish, and this example has been translated for this paper. 
See Figure 4 for examples of descriptions of the categories used and created in the analysis and of the levels in the combined hierarchy.

\subsection{Validity and reliability}

The manner in which the tests and the categories of answers are created is the main argument for validity, that is, this study has focused on construct validity (see discussions in sections 4.1 and 4.2 that relate the tests to theoretical aspects).

One reason for letting the participants write their answers to questions is to make it possible to include a larger number of participants. One could argue that oral answers would be more valid since the answers in such a situation could be of a more direct and spontaneous kind, thus more directly reflecting an existing mental representation and decreasing the risk of receiving answers based on mental representations that are being constructed when the question is asked. However, no method can in a direct manner examine a person's mental representations, and it is not evident how great the benefits are when answers are given orally. Also, written answers can allow a type of answer that oral answers cannot, namely the use of symbols that a person does not know how to pronounce.

The continuous alterations of (descriptions of) categories of answers were made in order to ensure a reliable coding process. A test of reliability of the result of the coding process could be to let several persons code (part of) the same data. However, since the categories in this study to some extent were created from the data set, that is, part of the data analysis was of a more qualitative and descriptive type, a more complete test of reliability would be too extensive for this study, since this would demand a recreation of categories by another person.

To study the tests' homogeneity, the correlation between the score on each question and the total score is calculated, among all 95 participants. For both mathematics and history, and 
for both types of tests, there is a positive and significant correlation between each question and the total score $(p<0.01$ for all, with Spearman's coefficient between 0.322 and 0.688$)$.

\subsection{Statistical analysis}

Even if the creation of a textbase in the mental representation is said to depend more on a general type of prior knowledge, a more specific type of prior knowledge (with respect to the content of the text) can of course also affect the textbase. Therefore it is essential to take the level of prior knowledge into account when comparing results of reading comprehension, even when focusing on the created textbase. In this way, the literacy skills can be separated from prior knowledge.

Four different groups of students are used in the analysis, S- and U-students who read the mathematical text either with or without symbols. For each student, the analysis of answers resulted in four measures, one for each of mathematics and history, of prior knowledge and reading comprehension. These groups and measures are used in a quantitative analysis in order to answer the questions formulated in Section 3. Correlations between different variables within one group and comparisons of one variable between different groups are performed. Since it cannot be presumed that the variables are normally distributed, nonparametric tests are used. Spearman's correlation coefficient is used when comparing two different variables within a group, where the coefficient $r_{s}$ is calculated. Mann-Whitney's Utest is used when comparing the same variable between different groups. For both these tests, a significance level of 0.05 is used in two-tailed tests for significance. 


\section{Results and analysis}

Table 1 shows the calculated correlations between prior knowledge and reading comprehension. As expected, better prior knowledge gives higher quality in the mental representation. It can be noted that the correlation coefficients for the different mathematical

texts are of the same magnitude. Thus, reading comprehension of the different mathematical texts is equally affected by differences in prior knowledge.

In the group of students who read the mathematical text without symbols $(N=49)$, there is a positive and significant correlation between reading comprehension for the mathematical and historical texts $\left(r_{s}=0.474, p=0.001\right)$. This correlation does not exist in the group who read the mathematical text with symbols $(p=0.698, N=46$ ). These results show a similarity in reading comprehension between the mathematical text without symbols and the historical text, and a difference in reading comprehension between the mathematical text with symbols and the historical text.

Table 1. Correlations between prior knowledge and reading comprehension for the three different texts.

\section{Mathematical text}
With symbols $(N=46)$
Without symbols $(N=49)$
Historical text $(N=95)$

$\begin{array}{lll}r_{s}=0.330^{*} & r_{s}=0.305^{*} & r_{s}=0.324^{* *} \\ p=0.025 & p=0.033 & p=0.001\end{array}$

* Significant correlation (level 0.05)

** Significant correlation (level 0.01) 
Table 2 shows the results from comparisons between the groups who read the two different mathematical texts. The groups have a similar level of prior knowledge but the students in the group who read the text without symbols have a better comprehension of the text. This result shows a difference in reading comprehension between the two types of mathematical texts. And since prior knowledge affects reading comprehension to a similar extent for both mathematical texts, there is some other type of knowledge or reading ability that creates this difference.

The comparisons between S-students and U-students for all three texts are summarized in Table 3. For the mathematical texts, the two groups of students have a similar level of prior knowledge, and for the text with symbols there is also no significant difference regarding reading comprehension. However, for the text without symbols there is a significant difference between the groups regarding reading comprehension. These results show that there is a type of knowledge or reading ability that is better developed among the U-students, but this knowledge or ability only affects the reading comprehension of the text without symbols.

Table 2. Comparisons of medians between groups who read different mathematical texts.

\section{Prior knowledge Reading comprehension}

Math text with symbols $(N=46)$

Math text without symbols $(N=49)$

Difference
8.0

0.0
3.0

$2.0^{*}$

\footnotetext{
* Significant difference (level 0.05)
} 
For the historical text (in Table 3), one can notice that the U-students in comparison to the S-students have lower prior knowledge but manage better in the test of reading comprehension. However, none of these differences are significant, but the difference in prior knowledge is close to the level of significance $(p=0.076)$. These results make it plausible that the U-students in fact have a better type of reading ability for the historical text.

The analysis of the results in Table 3 thus shows that the U-students seem to have a better

Table 3. Comparisons of medians between students from upper secondary level (S-students) and university students (U-students).

\section{Math text with symbols}

S-students $(N=30)$

U-students $(N=16)$

Difference

\section{Math text without symbols}

S-students $(N=31)$

U-students $(N=18)$

Difference

\section{Historical text}

S-students $(N=61)$

U-students $(N=34)$

Difference
0.5 $4.0^{*}$

* Significant difference (level 0.05) 
type of reading ability, compared to the S-students, an ability that affects the reading comprehension of the mathematical text without symbols and the historical text, but not the mathematical text with symbols. So, once again, the results show a difference in reading comprehension between the two mathematical texts, and a similarity between the mathematical text without symbols and the historical text.

\section{Conclusions and discussion}

Initially the results will be interpreted in relation to the two main research questions of this paper:

1. Since great similarities have been noticed between the mathematical text without symbols and the historical text, the content of the text (i.e., mathematics or history) does not affect the reading comprehension in a dominant way. Thus, the main component of the comprehension process for these texts is the more general literacy skills.

2. The clear differences between the two mathematical texts, together with the similarities between the mathematical text without symbols and the historical text, show that the reading process of the mathematical text with symbols is a special kind of comprehension process. Therefore, the main component of this comprehension process can be viewed as some type of content-specific literacy skill.

Thus, there is no common type of reading comprehension for mathematical texts in general, but one seems to need several types of skills for different types of mathematical texts. In particular, mathematical texts using symbols seem to demand a special type of skill for reading comprehension, while mathematical texts written in natural language do not seem to need any special type of skill except a more general reading ability. 
These conclusions can of course not be directly generalized to other types of texts or other groups of students. For example, the type of texts used in this study focus on conceptual understanding, and perhaps different results would emerge if texts are used that present and explain a procedure or an algorithm of some sort. Symbols can be said to have both a semantic meaning (like ordinary words) and an operational meaning, and one strength of symbols is the fact that the one "who can detach the semantic component of the symbols at will can work much more quickly with the symbols” (Pimm, 1989, p. 183). Such a detachment of the semantic component could perhaps be fatal when reading the text with symbols used in this study, but might be beneficial when reading a text that focuses on procedures. Thus, one way to explain the differences between the mathematical texts observed in this study can be that the students are expecting procedural descriptions when mathematical symbols are used in the text, and thereby they are reading the text in a different manner than other types of texts.

More generally, texts can use symbols in different ways, and therefore one needs to examine this usage in more detail before comparing different texts and before trying to draw any more general conclusions about the use of symbols in texts. But it is also important to take into account what kind of reading comprehension one focuses on when discussing different texts, and how one examines readers' understanding. Therefore, it is essential to have a theory of reading comprehension that makes it possible to define, and in more detail describe, what is meant by comprehending a text.

This study only shows an existence of a difference between reading comprehension of mathematical texts with and without symbols, but exactly what is causing this difference needs to be studied in more detail. The possibility that the students read the texts differently has been mentioned, but another possibility is that they are reading the texts in a too similar way, in that symbolic expressions and natural language do not follow the same syntactical and 
grammatical rules (Ernest, 1987) and therefore need to be read differently. However, these possibilities focus on the reading of the symbolic expressions themselves, but in this study the only conclusions that can be drawn refer to the difference between reading and comprehension of the whole texts. One can therefore distinguish between (i) different ways of comprehending symbols and symbolic expressions and how these ways can influence the comprehension of a whole text, and (ii) different ways the existence of symbols in a text can influence the reading strategies used by the reader. The phenomenon of 'temporary redundancy' can be taken as an example of the latter type of influence of the use of symbols in a text, when "a whole group of symbols are at one stage carried without reading, only to need detailed reading later" (Woodrow, 1982, p. 290). More research is needed of how this influence, and other possible types of influences by symbols, can affect the comprehension of the text.

The fact that there was no difference between university students and students from the upper secondary level regarding reading comprehension of mathematical texts with symbols, highlights the need for explicit teaching of reading symbolic texts, that is, more direct practice is needed for the development of the more content-specific literacy skills. On the other hand, the differences between the two groups of students for the other two texts suggest that the more general literacy skills seem to develop in a more natural way, presumably by the practice given by the more common needs and demands of reading texts written in natural language.

The results from this study can be compared to the similar study by Watkins $(1977,1979)$. The texts used by Watkins focus on conceptual understanding, but the questions used to examine the students' reading comprehension are different from the questions used in this study in two ways. Firstly, the questions do not ask for some information directly given in the text, and secondly the questions ask for an application of the information given in the text that 
is close to a type of procedural understanding of the text. Given these differences, it is interesting to note the different result regarding the use of symbols in the texts, where Watkins found that symbols could be advantageous for reading comprehension. But if this is due to the differences in questions asked, due to some difference in the groups of students with respect to prior knowledge, or due to something else is not easy to determine. One possible interpretation is that the use of symbols in mathematical texts can help the reader to form a type of procedural understanding that is more suitable for application-type problems, while the use of symbols might hinder the creation of a type of conceptual understanding that is more suitable for questions about the meaning of concepts. Regardless of different interpretations, the different types of questions used to investigate readers' comprehension highlight the need for a thorough and theory-based handling of reading comprehension, especially regarding what type of comprehension is examined. The use of a theory of different components of mental representations is one way of accomplishing this goal.

The participants in this study were not randomly selected. However, students came from different classes and schools and from different kinds of educational programmes at the university, and were not selected beforehand based on some characteristics, which makes it plausible that the group of participants is fairly normal compared to a larger population. At the same time it can be noted that the conclusions drawn are not highly dependent on a random selection, since focus is on the existence of certain phenomena, which is based on comparisons within the group of participants where a random selection was performed for the two types of mathematical texts. For example, the fact that for these students there is a clear difference between reading comprehension of the two mathematical texts is enough to conclude that there is no common homogenous type of reading comprehension for mathematical texts. But this study also shows that a more general type of knowledge or reading ability can be the main type of knowledge used when reading both certain 
mathematical texts and texts from other subject areas. That is, this study shows an existence of a great similarity between reading comprehension of these texts from different subject areas.

Finally, as the discussion has shown, the results of this study should of course not be interpreted to suggest that the use of mathematical symbols in texts is undesirable and that all textbooks should be using natural language instead. On the contrary, one of the greatest strengths of mathematics is the use of a symbolic language, but if reading comprehension of texts using this language is not developed among students, this strength will not emerge for them.

\section{Acknowledgements}

I would like to thank Christer Bergsten for all constructive comments and guidance when writing this paper as well as when conducting the research study presented in this paper. I would also like to thank Norma Presmeg for valuable comments on this paper.

\section{Notes}

1. The survey included references that in some way referred to properties of mathematical texts or the reading of mathematical texts. However, literature only dealing with the symbolic language of mathematics was not included since the main purpose was to examine more general aspects of mathematical texts. A time period of 35 years is included in the references, from Kane (1968) to Adams (2003), and different levels in the educational system are included, from younger children (Shuard and Rothery, 1984) to university students (Defence, 1994). However, no claim is made that the survey has covered all relevant literature. 
2. In this paper, students' nonsense answers are taken as signs of unwillingness to complete the task, and the results from these students are therefore excluded. But these answers could also be interpreted as a (complete) lack of comprehension. However, a repeated data analysis including these few students did not affect the significances of the relationships discussed in this paper.

\section{References}

Adams, T.L.: 2003, 'Reading mathematics: More than words can say’, The Reading Teacher 56 (8), 786-795.

Borasi, R. and Siegel, M.: 1990, 'Reading to learn mathematics: New connections, new questions, new challenges', For the Learning of Mathematics 10 (3), 9-16.

Borasi, R. and Siegel, M.: 1994, 'Reading, writing and mathematics: rethinking the "basics” and their relationship', in F. Robitaille, D.H. Wheeler and C. Kieran (eds.), Selected Lectures From the 7th International Congress on Mathematical Education: Québec, 1723 August 1992, Presses de l'Université Laval, Sainte-Foy [Québec], pp. 35-48.

Brunner, R.B.: 1976, ‘Reading mathematical exposition’, Educational Research 18, 208-213.

Brändström, A.: 2005, Differentiated Tasks in Mathematics Textbooks: An Analysis of the Levels of Difficulty, Licentiate Thesis, Department of Mathematics, Luleå University of Technology, Luleå, Sweden. Retrieved November 14, 2005, from http://epubl.ltu.se/14021757/2005/18/LTU-LIC-0518-SE.pdf

Cowen, C.C.: 1991, 'Teaching and testing mathematics reading', American Mathematical Monthly 98 (1), 50-53. 
Defence, A.: 1994, The Readability of the Mathematics Textbook: With Special Reference to the Mature Student, Master Theses, The Department of Mathematics and Statistics, Concordia University, Montreal, Quebec, Canada. Retrieved November 14, 2005, from http://www.nlc-bnc.ca/obj/s4/f2/dsk3/ftp04/MQ44873.pdf

Ernest, P.: 1987, ‘A model of the cognitive meaning of mathematical expressions', The British Journal of Educational Psychology 57, 343-370.

Fenwick, C.: 2001, 'Students and their learning from reading', Humanistic Mathematics Network Journal 24, 52-58.

Foxman, D.: 1999, Mathematics Textbooks Across the World: Some Evidence From the Third International Mathematics and Science Study (TIMSS), National Federation for Educational Research, Slough.

Fuentes, P.: 1998, ‘Reading comprehension in mathematics', Clearing House 72 (2), 81-88.

Hubbard, R.: 1990, ‘Teaching mathematics reading and study skills', International Journal of Mathematical Education in Science and Technology 21, 265-269.

Johansson, M.: 2003, Textbooks in Mathematics Education: A Study of Textbooks as the Potentially Implemented Curriculum, Licentiate Thesis, Department of Mathematics, Luleå University of Technology, Luleå, Sweden. Retrieved November 14, 2005, from http://epubl.luth.se/1402-1757/2003/65/LTU-LIC-0365-SE.pdf

Kane, R.B.: 1968, 'The readability of mathematical English', Journal of Research in Science Teaching 5, 296-298.

Kintsch, W.: 1994, 'Text comprehension, memory, and learning’, American Psychologist 49, 294-303. 
Kintsch, W.: 1998, Comprehension: A Paradigm for Cognition, Cambridge University Press, Cambridge.

Konior, J.: 1993, 'Research into the construction of mathematical texts', Educational Studies in Mathematics 24, 251-256.

Krygowska, Z.: 1969, 'Le texte mathématique dans l'enseignement', Educational Studies in Mathematics 2, 360-370.

Langer, J.A.: 1984, 'Examining background knowledge and text comprehension', Reading Research Quarterly 19, 468-481.

Lithner, J.: 2004, 'Mathematical reasoning in calculus textbook exercises', Journal of Mathematical Behavior 23, 405-427.

Lorch, R.F. and van den Broek, P.: 1997, 'Understanding reading comprehension: current and future contributions of cognitive science', Contemporary Educational Psychology 22, 213-246.

Love, E. and Pimm, D.: 1996, 'This is so: a text on texts', in A.J. Bishop et al. (eds.), International Handbook of Mathematics Education, Kluwer, Dordrecht, pp. 371-409.

McKenna, M.C. and Robinson, R.D.: 1990, 'Content literacy: a definition and implications', Journal of Reading 34, 184-186.

Morgan, C.: 1998, Writing Mathematically: The Discourse of Investigation, Falmer, London.

Niss, M. and Højgaard Jensen, T. (eds.): 2002, Kompetencer og matematiklcering - ideer og inspiration til udvikling af matematikundervisning i Danmark, Report no. 18 - 2002, Undervisningsministeriets forlag, Copenhagen. Retrieved November 14, 2005, from http://pub.uvm.dk/2002/kom/hel.pdf 
Pimm, D.: 1989, Speaking Mathematically: Communication in Mathematics Classrooms (paperback edition), Routledge, London.

Shuard, H. and Rothery, A.: 1984, Children Reading Mathematics, London: Murray.

Solomon, Y. and O'Neill, J.: 1998, ‘Mathematics and narratives', Language and Education 12 (3), 210-221. Retrieved November 14, 2005, from http://www.channelviewpublications.net/le/012/0210/le0120210.pdf

Turnau, S.: 1983, ‘The mathematical textbook - a problem of mathematics education’, ZDM Zentralblatt für Didaktik der Mathematik 15 (4), 168-173.

Van Dijk, T.A. and Kintsch, W.: 1983, Strategies of Discourse Comprehension, Academic Press, New York.

Van Oostendorp, H. and Goldman, S.R. (eds.): 1998, The Construction of Mental Representations During Reading, Lawrence Erlbaum Associates, Mahwah, N.J.

Watkins, A.E.: 1977, The Effect of the Symbols and Structures of Mathematical English on the Reading Comprehension of College Students, Doctoral Dissertation, University of California, Los Angeles.

Watkins, A.E.: 1979, 'The symbols and grammatical structures of mathematical English and the reading comprehension of college students', Journal for Research in Mathematics Education 10, 216-218.

Weaver, C.A., Mannes, S. and Fletcher, C.R. (eds.): 1995, Discourse Comprehension: Essays in Honor of Walter Kintsch, Erlbaum, Hillsdale.

Vidal-Abarca, E., Martínez, G. and Gilabert, R.: 2000, 'Two procedures to improve instructional text: effects on memory and learning', Journal of Educational Psychology 92 (1), 107-116.

Woodrow, D.: 1982, ‘Mathematical symbolism’, Visible Language 16, 289-302. 
Österholm, M.: 2004, Läsa matematiska texter: Förståelse och lärande i läsprocessen [Reading Mathematical Texts: Understanding and Learning in the Reading Process], Licentiate Thesis, Department of Mathematics, Linköping University, Linköping, Sweden. Retrieved November 14, 2005, from http://www.ep.liu.se/lic/science_technology/11/34/digest.pdf 